\title{
Pitfalls of cannulation for extracorporeal life support: review of the literature and illustrative case presentation
}

\author{
Martin Geyer ${ }^{1}(\mathbb{1}) \cdot$ Bernhard Gohrbandt $^{2} \cdot$ Ingo Sagoschen $^{1} \cdot$ Thomas Hartmann $^{3}$ • \\ Felix Post $^{4} \cdot$ Christian-Friedrich Vahl $^{3} \cdot$ Thomas Münzel $^{1}$
}

Received: 20 November 2016 / Accepted: 5 October 2017 / Published online: 9 November 2017

(C) The Japanese Society for Artificial Organs 2017

\begin{abstract}
Extracorporeal membrane oxygenation (ECMO) and extracorporeal life support (ECLS) are an increasingly established advanced therapy for emerging severe lung and/ or cardiocirculatory dysfunction or failure. Several reports have provided evidence for a potential benefit in prognosis by ECLS in cases of cardiogenic shock including cardiopulmonary resuscitation. Routine use in specialized centers reduces the incidence of negative side effects (e.g., vascular/ischemic, embolic, hemorrhagic, hemolytic and, furthermore, septic). Vascular complications like not only limb ischemia but also hypoxia proximal to the cannulation site up to complete sectorial hypoxia called "harlequin phenomenon" could refer to be a major adverse event in ECLS which, therefore, should be limited primarily to cardiocirculatory indications. Here we report on a case with "harlequin phenomenon" after ECLS implementation as a relevant complication of the mode of cannulation and review benefits and risks of commonly used variants of vascular access.
\end{abstract}

Martin Geyer

martin.geyer@unimedizin-mainz.de

1 Center for Cardiology, Cardiology I, University Medical Center Mainz, Johannes Gutenberg-University Mainz, Langenbeckstr. 1, 55131 Mainz, Germany

2 Department of Thoracic Surgery, Katholisches Klinikum Mainz, An der Goldgrube 11, 55131 Mainz, Germany

3 Department of Cardiothoracic and Vascular Surgery, University Medical Center Mainz, Johannes Gutenberg-University Mainz, Langenbeckstr. 1, 55131 Mainz, Germany

4 Department of Medicine, Cardiology and Intensive Care Medicine, Katholisches Klinikum Koblenz-Montabaur, Rudolf-Virchow-Str. 7-9, 56073 Koblenz, Germany
Keywords ECLS $\cdot$ ECMO $\cdot$ Complication by cannulation $\cdot$ Harlequin phenomenon $\cdot$ Sectorial hypoxia

$\begin{array}{ll}\text { Abbreviations } \\ \text { ARDS } & \text { Acute respiratory distress syndrome } \\ \text { AV } & \text { Arterio-venous (cannulation) } \\ \text { cCT } & \text { Cranial computed tomography } \\ \text { CNS } & \text { Central nervous system } \\ \text { CPR } & \text { Cardiopulmonary resuscitation } \\ \text { DLC } & \text { Double lumen cannula } \\ \text { D }_{\text {LCO }} & \text { Diffusion capacity (of the lung) for carbon } \\ & \text { monoxide } \\ \text { ECCO } & \text { R } \\ \text { ECLS } & \text { Extracorporeal carbon dioxide removal } \\ \text { ECMO } & \text { Extracorporeal life support } \\ \text { EEG } & \text { Electroencephalogram } \\ \text { ELSO } & \text { Extracorporeal life support organization } \\ \text { FVC } & \text { Forced vital capacity } \\ \text { IABP } & \text { Intra-aortic balloon pump } \\ \text { ICU } & \text { Intensive care unit } \\ \text { ILA } & \text { Interventional lung assist }{ }^{\circledR} \text { (Trademark by } \\ & \text { Novalung }{ }^{\circledR}, \text { Heilbronn, Germany) } \\ \text { MBP } & \text { Mean blood pressure } \\ \text { NIRS } & \text { Near-infrared spectroscopy } \\ \text { NSE } & \text { Neuron-specific enolase } \\ \text { pECLA } & \text { Pumpless extracorporeal lung assist } \\ \text { PEA } & \text { Pulseless electric activity } \\ \text { PEEP } & \text { Positive end-expiratory pressure } \\ \text { SAVE } & \text { Survival after veno-arterial ECMO (score) } \\ \text { VA } & \text { Veno-arterial (cannulation) } \\ \text { VV } & \text { Veno-venous (cannulation) } \\ \text { VVA } & \text { Veno-veno-arterial (cannulation) }\end{array}$

Arterio-venous (cannulation)

mography

CPR Cardiopulmonary resuscitation

DLC Double lumen cannula

$\mathrm{D}_{\mathrm{LCO}} \quad$ Diffusion capacity (of the lung) for carbon

$\mathrm{ECCO}_{2} \mathrm{R}$ Extracorporeal carbon dioxide removal

ECLS Extracorporeal life support

ECMO Extracorporeal membrane oxygenation

EEG Electroencephalogram

ELSO Extracorporeal life support organization

FVC Forced vital capacity

IABP Intra-aortic balloon pump

ICU Intensive care unit

ILA Interventional lung assist ${ }^{\circledR}$ (Trademark by

MBP Mean blood pressure

NIRS Near-infrared spectroscopy

NSE Neuron-specific enolase

pECLA Pumpless extracorporeal lung assist

PEA Pulseless electric activity

PEEP Positive end-expiratory pressure

SAVE Survival after veno-arterial ECMO (score)

VA Veno-arterial (cannulation)

VVA Veno-veno-arterial (cannulation) 


\section{Introduction}

Extracorporeal augmenting systems are a relatively simple construction to enable lung or cardiocirculatory support. The main contents are an artificial membrane oxygenator and a centrifugal pumping system promoting blood via heparincoated lines. A heat exchanger regulates body temperature. In the late 1970s, small cardiopulmonary bypass systemsthe first so-called extracorporeal membrane oxygenation (ECMO) systems-were introduced as a rescue therapy for severe ARDS and cardiogenic shock. First prospective randomized trials in the 1970s and 1990s documented a lack of benefit in mortality in ARDS due to a high rate of complications [1,2]. Technical advances as miniaturized centrifugal pumps in reservoir-free systems avoiding blood-air contact and heparin-coated lines were the cornerstones in significantly reducing the adverse effects. CESAR was the first randomized trial to show a reduction in mortality with use of ECMO in severe ARDS [3]. Even though the study design was criticized (e.g., the control cohort was not treated in the same center and on the same ventilation protocol as the ECMO-cohort) the result was fortified by a vast majority of reports and registers on the successful use of ECMO in H1N1-pandemia in 2009.

Nomenclature is not standardized: commonly the term "ECMO" designates systems for indications of respiratory failure whereas "ECLS" (formerly also depicted as "VA-ECMO") refers to devices used for cardiocirculatory support. Systems are characterized by type and site of cannulation: open-surgical/peripheral; veno-venous (VV)/ veno-arterial (VA)/veno-venous-arterial(VVA)/arteriovenous (AV). ECMO-Function is mainly defined by bloodflow: high-flow (not clearly defined: usually more than $\sim 60 \%$ of heart volume), mid-flow and low-flow systems including pumpless devices. Three principal functions are to be elucidated individually: $\mathrm{CO}_{2}$-removal mainly depends on sweep gas flow and is highly-effective even in low-flow systems, whereas body oxygenation is predominantly dependent on blood flow and thus can only be achieved in high-flow-systems; cardiocirculatory support is enabled by veno-arterious cannulation (Table 1). Double lumen venous cannulas (DLC) are available for ECMO to facilitate mid-flow up to full lung support by only single cannulation (size up to 32F), usually via the jugular vein. Main field of DLC-application might be awake patients requiring extracorporeal gas exchange to avoid or wean from mechanical ventilation [4]. ECLS bears more side effects in comparison to veno-venous support due to possible ischemic complications and by increasing cardiac afterload. Therefore, its indication should be limited to conditions of cardiac failure or resuscitation efforts [5]. Different modes of cannulation in extracorporeal augmenting systems can account for a several problems which can influence and threaten the whole clinical course of the patient. Our review aims on providing a differentiated view on aspects that have to be taken into account regarding different modes of vascular access in ECLS and enlightens potential solution strategies for reversible cannulaassociated complications illustrated by a special complication in a case of unilateral hypoxia under extracorporeal augmentation.

Table 1 Types and function of extracorporeal augmenting systems (ECLS, ECMO, ECCO 2 R, pECLA)

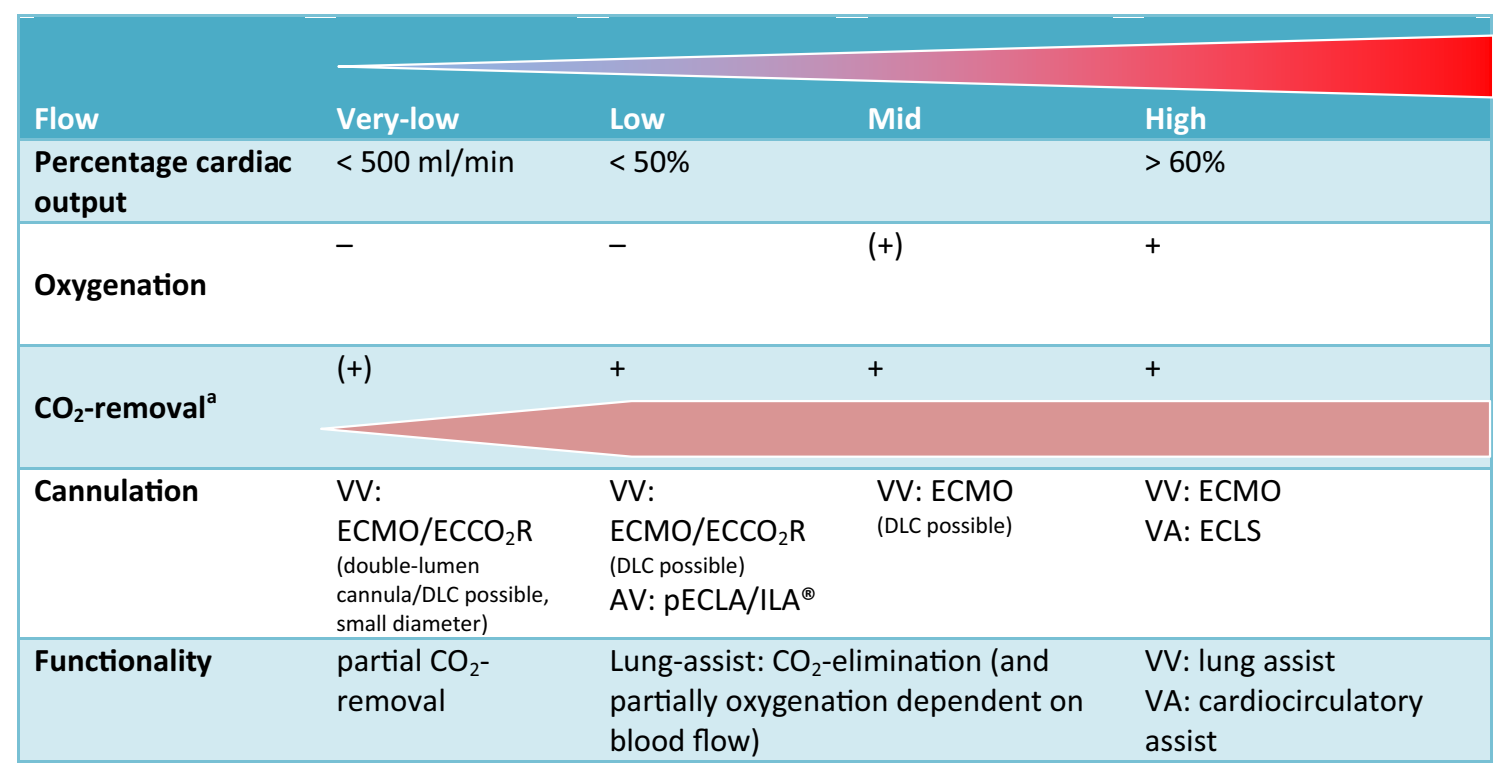

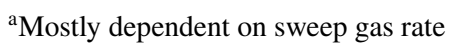




\section{Case report}

A 53-year-old male patient was admitted for respiratory failure caused by pneumonia with pneumocystis jirovecii under immune suppression for idiopathic lung fibrosis. Preliminary screening exams had proven an advanced stage of lung fibrosis (typical lung morphology changes in CT scan, severe lung restriction/FVC of $42 \%$ predicted, severely impaired CO-diffusion capacity/ $\mathrm{D}_{\mathrm{LCO}}$ of $27 \%$ ) going along with echocardiographic signs of moderate right ventricular dysfunction as a result of precapillary pulmonary hypertension (documented by right heart catheterization), whereas left ventricular function had been normal and a relevant coronary artery disease had been excluded by invasive evaluation. Assessment as a candidate for potential lung transplantation was nearly completed and a potential implantation of ECMO for lung support as bridge to further decision, improvement, or transplantation had already been under discussion. During initial clinical course on the pulmonary ward an interstitial pneumonia had resulted in progressive deterioration of arterial oxygenation on high-volume oxygen therapy going along with orthopnea and hyperventilation. Pneumocystis jirovecii could be cultivated in bronchoalveolar lavage and was treated accordingly. After transferal on our intensive care unit only transient stabilization was achieved by non-invasive ventilation. In respiratory exhaustion and emerging severe hypoxia, intubation and mechanical ventilation was urgent. During intubation, the patient developed cardiac arrest due to pulseless electrical activity and cardiopulmonary resuscitation was started. Thus, the original plan towards ECMO support had to bet abandoned and switched to ECLS implantation during resuscitation efforts. Vascular access was performed via femoroarterial cannulation in Seldinger's technique-which turned out to be challenging under conditions of cardiac arrest as the identification of the arteria was more difficult and furthermore venous cannula could not be inserted easily at first. After a total of $50 \mathrm{~min}$ of CPR a sufficient blood pressure (MBP) and oxygenation could finally be achieved under adequate flow ECLS. As blood gas analysis obtained from the right radial artery revealed insufficient oxygenation and to prevent subsequent sectorial hypoxia of the supraaortic region a second arterial access via the right subclavian artery was implemented a few hours later (ECLS settings: blood flow $4.7 \mathrm{~L}$ min, sweep gas flow $5 \mathrm{~L} / \mathrm{min}, \mathrm{FiO}_{2} 0.6$; respirator settings: controlled ventilation, Pmax/mean 28/10 mbar, $\mathrm{FiO}_{2}$ 0.35). A targeted temperature management including mild hypothermia over $24 \mathrm{~h}$ was maintained. Echocardiographic monitoring showed subsequent reconstitution of left ventricular function concomitant to increasing amplitude of blood pressure curves in the following days. The patient developed a visible and measurable sectorial hypoxia of the left upper quadrant (Fig. 1), which was completely reversible when clamping the femoroarterial ECLS lining on trial and sole perfusion via the right subclavian cannula. As a consequence, the femoroarterial cannula was surgically removed. Mechanical ventilation was also intensified. Due to relevant bleeding and hemodynamic instability during cannula explantation the initial plan to switch to veno-venous cannulation was discarded. The patient developed relevant ischemic complications distal to the femoral cannulation site. Reducing the medication for sedation unmasked an increasing incidence of myocloni and lacking signs of consciousness. NSE values were significantly elevated (289 ng/ $\mathrm{ml}$, normal range $<12.5 \mathrm{ng} / \mathrm{ml}$ ). However, the threshold for determination of neurologic prognosis after circulatory arrest by biomarkers might be influenced by extracorporeal augmentation systems [6, 7]. In accordance with the clinical examination, EEG and cCT indicated a fatal neurologic prognosis. Furthermore, the patient developed progressive multi-organ failure and died on day 6 after resuscitation on the continuation of maximum-flow ECLS.

\section{Discussion}

Extracorporeal augmentation systems can be implemented easily in situations of emerging respiratory and cardiocirculatory failure, but the systems for themselves potentially entail life-threatening adverse events. The ELSO Registry, the largest international database on ECLS, reports on an overall survival of $56 \%$ (cardiac indications) to $66 \%$ (pulmonary indications) [8]. These data, indicating a relatively low mortality in relation to disease severity, the successful use of ECMO in the CESAR trial as well register data on an ECMO use for pulmonary failure, e.g., in the H1N1 pandemia, and furthermore promising reports on ECLS use for cardiac failure strongly confirm the relevance of extracorporeal augmenting systems. Their availability in centers has also markedly increased in the last years. Complications include renal failure (52\%), bleeding (33\%), pneumonia (33\%), oxygenator dysfunction (29\%), sepsis (26\%), hemolysis (18\%), limb ischemia (10\%), thrombosis (10\%), CNS complications (8\%), gastrointestinal bleeding (7\%) and disseminated intravascular coagulation (5\%) [9] (Table 2). Vascular complications in kind of cannula-site bleeding and peripheral ischemia are frequent; overall ranges vary from $8.4 \%$ [10] to $25 \%$ [11]. These go along with a significant lower survival of $43 \%$ ("respiratory"), respectively, 27\% ("cardiac ECLS") in adults [12]. Risk factors comprise peripheral and arterial cannulation, a mismatch in lumen of catheter and vessel, and a history of arteriosclerotic disease. In $50-100 \%$ of reported events a fasciotomia and in $0.2-1.4 \%$ an amputation was necessary for compartment syndrome [13]. 


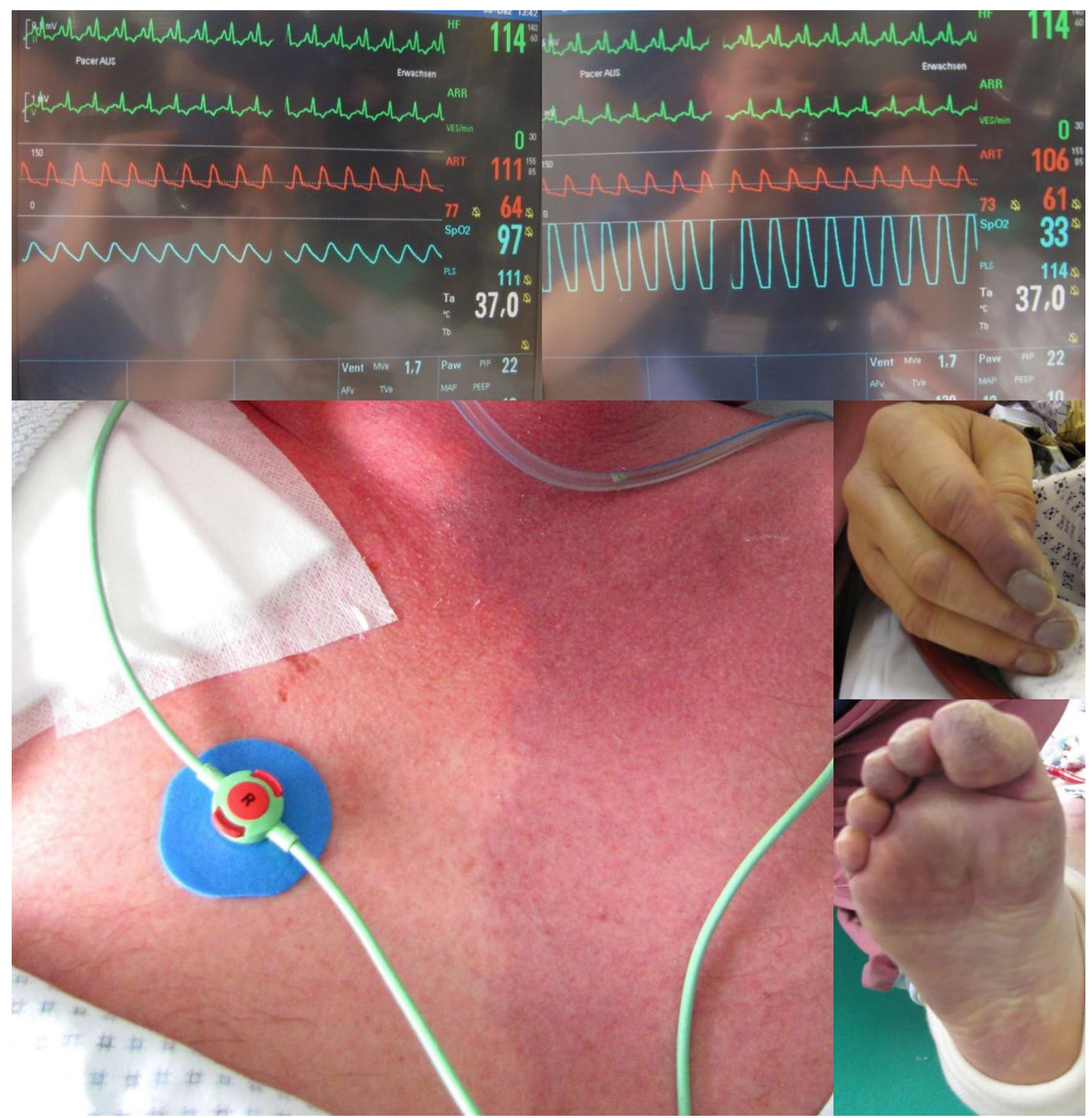

Fig. 1 Case of an untypical "harlequin phenomenon". Untypical "harlequin phenomenon": sectorial hypoxia of the left upper quadrant with a significant difference in oxygen saturation to the other side. Critical ischemia of right foot and right hand due to arterial cannulation

\section{Location and types of cannulation}

A variety of vascular accesses in adult ECLS are feasible and established (Table 3). The predominant access site for arterial cannulation is the femoral followed by subclavian/ axillary artery. Open-surgical cannulation can be performed via the ascending aorta, pulmonary artery or right atrium. Typically, venous cannulas are 19-23 F in diameter and $38-55 \mathrm{~cm}$ in length. Arterial cannulas are usually smaller $(15-17 \mathrm{~F}$, sometimes up to $21 \mathrm{~F})$ and shorter $(15-23 \mathrm{~cm})$. Since femoral vessels are easy to locate and cannulation can instantly be performed by Seldinger's technique, this access is the preferred mode in emergency situations including ongoing CPR. However, cannulation during ongoing CPR might sometimes pose a challenge. In our patient, it took $50 \mathrm{~min}$ to achieve sufficient hemodynamic stabilization. As outlined by our case, during resuscitation efforts it is crucial to take the pro/con decision for ECLS implementation early into consideration.

Pragmatic strategies have been established to prevent cannula-associated problems. Transcutaneous approach should be carried out with ultrasound guidance [14]. A retrospective study on femoral access using a smaller arterial cannula (15 F versus $17-24 \mathrm{~F}$ ) reduced the incidence of cannula-site bleeding [15]. The installation of an antegrade perfusion line (e.g., 5-6 F sheath introducer, see Fig. 2) is 
Table 2 Complications in extracorporeal augmenting systems (ECLS and ECMO, adopted from [9])

\begin{tabular}{llc}
\hline Outcome & $\begin{array}{l}\text { No. of studies reporting out- } \\
\text { come (no. of patients) }\end{array}$ & $\begin{array}{l}\text { Summary point esti- } \\
\text { mate (95\% CI) (\%) }\end{array}$ \\
\hline Mortality & & \\
Overall & $12(1763)$ & $54(47-61)$ \\
During ECMO & $8(1059)$ & $45(42-48)$ \\
After ECMO & $5(734)$ & $13(11-15)$ \\
Complications & & \\
Aspiration pneumonia & $3(495)$ & $5(3-7)$ \\
Bacterial pneumonia & $4(825)$ & $33(30-36)$ \\
Bleeding & $5(946)$ & $33 \%(30-36 \%)$ \\
Central nervous system complications & $5(720)$ & $8(6-10)$ \\
Disseminated intravascular coagulation & $3(510)$ & $5 \%(3-7 \%)$ \\
Gastrointestinal bleeding & $4(610)$ & $7(5-9)$ \\
Hemolysis & $4(610)$ & $18(15-21)$ \\
Leg ischaemia & $5(856)$ & $10(8-12)$ \\
Liver dysfunction & $4(610)$ & $16(13-19)$ \\
Oxygenator dysfunction requiring replacement & $5(946)$ & $29(26-32)$ \\
Renal failure requiring continuous veno-venous & $6(828)$ & $52(49-55)$ \\
haemofiltration & & $26(23-29)$ \\
Sepsis & $5(940)$ & $10(5-15)$ \\
Venous thrombosis & $1(127)$ & \\
\hline
\end{tabular}

Table 3 Typical forms of vascular access in ECLS (modified from [13])

\begin{tabular}{|c|c|c|c|c|c|c|c|c|c|}
\hline & \multirow[t]{2}{*}{ Method } & \multicolumn{4}{|l|}{ Arterial cannula } & \multicolumn{2}{|c|}{ Venous cannula } & \multirow[t]{2}{*}{ Possible complications } & \multirow{2}{*}{$\begin{array}{l}\text { Possible } \\
\text { manage- } \\
\text { ment strate- } \\
\text { gies }\end{array}$} \\
\hline & & Vascular access & & Cannula s & & $\begin{array}{l}\text { Vascular } \\
\text { access }\end{array}$ & $\begin{array}{l}\text { Cannula } \\
\text { size }\end{array}$ & & \\
\hline \multirow[t]{2}{*}{ Central } & \multirow[t]{6}{*}{$\begin{array}{l}\text { Surgi- } \\
\text { cally }\end{array}$} & \multicolumn{2}{|l|}{$\begin{array}{l}\text { Aorta ascen- } \\
\text { dens }\end{array}$} & \multicolumn{2}{|l|}{$19-23 \mathrm{~F}$} & \multirow[t]{2}{*}{$\begin{array}{l}\text { Right } \\
\text { Atrium } \\
\text { appen- } \\
\text { dix }\end{array}$} & \multirow[t]{2}{*}{$32 / 40 \mathrm{~F}$} & $\begin{array}{l}\text { Infections } \\
\text { Bleeding } \\
\text { Resternotomy complications } \\
\text { Mediastinitis }\end{array}$ & \\
\hline & & A. pulmonalis & & $\begin{array}{l}15-17 \mathrm{~F} \\
(19- \\
21 \mathrm{~F})\end{array}$ & $21-23 \mathrm{~F}^{\mathrm{a}}$ & & & & \\
\hline \multirow[t]{6}{*}{ Peripheral } & & $\begin{array}{l}\text { Right A. } \\
\text { subclavia }\end{array}$ & $\begin{array}{l}\text { + optional } \\
\text { vascular } \\
\text { prosthe- }\end{array}$ & & & $\begin{array}{l}\text { V. femo- } \\
\text { ralis }\end{array}$ & $19-23 \mathrm{~F}$ & $\begin{array}{l}\text { Peripheral ischemia } \\
\text { Steal phenomenon }\end{array}$ & $\begin{array}{l}\text { Insertion of } \\
\text { Dacron } \\
\text { patch }\end{array}$ \\
\hline & & & sis & & & & & Compartment syndrome & Fasciotomia \\
\hline & & & & & & & & Hyperperfusion & $\begin{array}{l}\text { Umbilical } \\
\text { tape distal } \\
\text { to graft }\end{array}$ \\
\hline & & & & & & & & Bleeding & \\
\hline & \multirow[t]{2}{*}{$\begin{array}{l}\text { Seld- } \\
\text { inger } \\
\text { (or } \\
\text { surgi- } \\
\text { cally) }\end{array}$} & \multirow{2}{*}{\multicolumn{2}{|c|}{$\begin{array}{l}\text { A. femora- } \\
\text { lis }+ \text { ante- } \\
\text { grade perfu- } \\
\text { sion line }\end{array}$}} & \multirow{2}{*}{\multicolumn{2}{|c|}{$\begin{array}{l}15-17(19-21) \mathrm{F} \\
+6-14 \mathrm{~F} \text { antegr. } \\
\text { perfusion line }\end{array}$}} & & & Unilateral hypoxia & $\begin{array}{l}\text { Switch to } \\
\text { axillary } \\
\text { or central } \\
\text { cannula- } \\
\text { tion or } \\
\text { VVA? }\end{array}$ \\
\hline & & & & & & & & Leg ischemia & $\begin{array}{l}\text { Antegrade } \\
\text { perfusion } \\
\text { line }\end{array}$ \\
\hline
\end{tabular}

\footnotetext{
${ }^{\mathrm{a}}$ In case of vascular prosthesis with diameter of $8 \mathrm{~mm}$
} 
Fig. 2 Pathophysiology in untypical "harlequin phenomenon". Proposed mechanism of sectorial hypoxia in the untypical "harlequin phenomenon": the competition of the retrograde flow of oxygenated blood by ECLS and the reconstituting left ventricular ejection of insufficiently oxygenated blood under persistent pulmonary insufficiency may potentially result in hypoxia of the upper aortic region. Whereas the right upper quadrant is sufficiently oxygenated by perfusion through the auxiliary subclavian arterial cannula, the left upper quadrant remains cyanotic. Note: a $6 \mathrm{~F}$ sheath introducer was used as additional antegrade perfusion line in femoroarterial cannulation

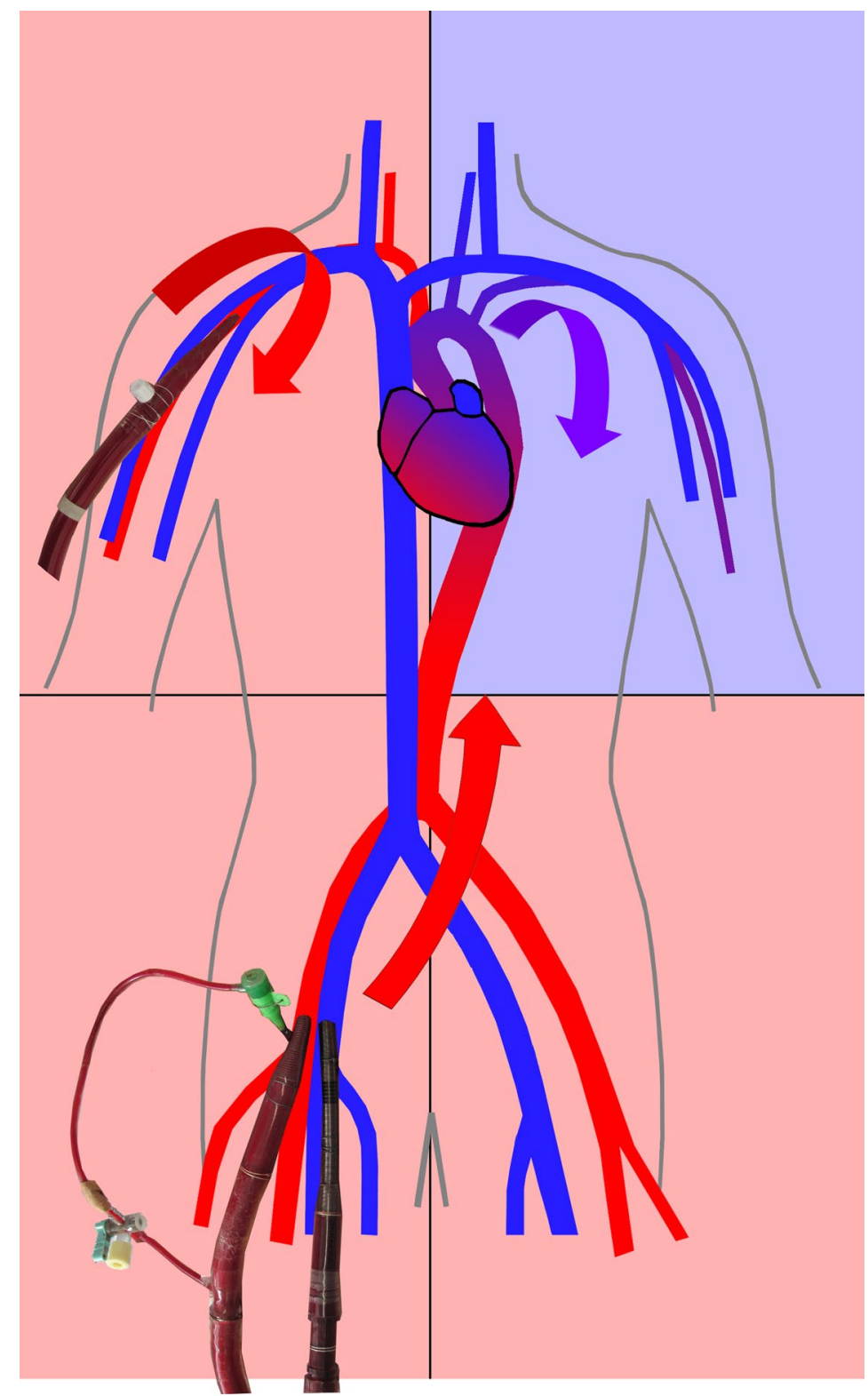

strictly recommended to maintain sufficient perfusion of the cannulated leg [5]. Arteriosclerotic or aneurysmatic disease might be seen as relative contraindication; here cannulation of the axillar or subclavian artery might bear a lower risk of embolization or ischemic complications. Moreover, under conditions of pelvic trauma or even anticipating the aspect of mobilization a possibly more "upstream" mode of access in comparison to the femoral vessels might be a more reasonable choice in selected patients. Specific complications of the axillary/subclavian access comprise ipsilateral arm swelling and hyperperfusion up to compartment syndrome [16]; an interposition of a Dacron patch might reduce peripheral complications here [17]. Nevertheless, the major disadvantage of this access might be that it is mandatorily carried out surgically as well as its later removal. Severely obese patients might not be eligible for this approach. An alternative surgical option of vascular access is the cannulation of the ascending aorta-mostly used for prolonged weaning from cardiopulmonary bypass after cardiac surgery. However, higher incidents of bleeding and resternotomy as well as infections have been observed [18]. The overall percentage of cannula-associated complications seems to be independent of the implantation technique as well as the duration of ECLS support [10].

\section{Upstream or sectorial hypoxia}

Most relevant problems occur "downstream" to the cannulation site. "Upstream" ischemias are a potential side effect of femoroarterial access in cardiac failure: organ perfusion 
is achieved via retrograde aortic flow. In cases of concomitantly impaired pulmonary gas exchange (e.g., by primary pulmonary diseases, lung edema, inadequate ventilator settings), a progressive recovery of left ventricular function may potentially result in an increased low-saturated antegrade blood flow in the proximal sections of the aorta competing retrograde ECLS flow building a "watershead" in the aorta. This may lead to a sectorial hypoxia demarking visible cyanosis in the upstream region of the aorta: the right upper body quadrant including the coronary arteries and the right arm, occasionally including the brain and even the left arm. In analogy to a rare autonomic disorder (paroxystic unilateral change in skin color due to relative hypothalamic control immaturity in the newborn or acquired lesions of the sympathetic nervous system resulting in impaired vegetative innervation) this adverse event has been named "harlequin phenomenon" (also referred to as "north-south-syndrome"). Recently, a "two-circuit" pathomechanism of "harlequin phenomenon" has been proposed in an animal model, suggesting that deoxygenation of the upper part in femoroarterial ECLS is not only a result from the competing arterial flow in the aorta, but also caused by the return of extremely low-saturated venous blood to the upper part of the body [19]. As the possibly impaired saturation of the coronary and cerebral blood flow cannot be measured easily, ELSO guidelines recommend invasive measurement of $\mathrm{O}_{2}$ saturation in the right radial artery as most upstream site available [6]. Measurement of cerebral blood oxygenation by near-infrared spectroscopy (NIRS) might be helpful, although its clinical impact on ECLS is still to be determined.

As demonstrated by our case, several solution strategies of unilateral hypoxia should be discussed based on its proposed pathophysiology depending on the patient's preconditions: aware of the arising potential complication of femoroarterial access, we implanted a second arterial cannula into the subclavian artery, as cardiac recovery was expected. Even more, we were astounded to be faced by a kind of untypical "harlequin phenomenon" with a remarkable sectorial hypoxia of the left upper body quadrant that evolved (Fig. 1). The most suggestive explanation of this unexpected finding might have been a hypoxia in the region of the "watershed" in the descending aorta by concurrence of streams of antegrade hypoxic blood flow by the recovering left ventricle and the retrograde perfusion via the femoroarterial cannula while the right upper quadrant was sufficiently oxygenated via the right subclavian cannula (Fig. 2). On the one hand, ECLS support was divided nearly by half in an antegrade and a retrograde stream by dual cannulation; on the other hand, a progressive fraction of low-saturated blood originating from the left ventricle caused by increasing stroke volumes going along with concomitant enduring lung dysfunction mixed with ECLS blood streams, which resulted in this unexpected adverse effect. The phenomenon was not apparent initially, but evolved a few days later under progressive left ventricular output and ongoing profound pulmonary insufficiency. To which extent cerebral circulation was affected could not be clarified finally - at least, EEG showed no hemispheric differences. The problem was solved by explantation of the femoarterial cannula and sole "antegrade" extracorporeal support. In general, profound impairment of gas exchange is the relevant precondition of a unilateral hypoxia; this should be especially considered in ECLS for patients under advanced stages of lung diseases like in our case of pulmonary fibrosis. Thus, possible solution strategies should also address the proposed cause for impaired pulmonary oxygenation and exhaust all possibilities for optimization. Additionally, alternative pathomechanisms should be carefully discussed in cases of profound hypoxia under ECLS support including pulmonary vascular malformations or arterial shunts-these were not detected on CT scan in our case, supporting our thesis of a mainly cannulation-associated problem.

Several publications have assessed the relevance of increased cardiac afterload by ECLS - a problem becoming relevant during reconstitution of left ventricular ejection and possibly leading to pulmonary edema. The combination of ECLS and additional left ventricular assist devices working "antegrade" (IABP, Impella ${ }^{\circledR}$ ) has been investigated to be effective in reducing the cardiac afterload [20,21], while the impact on cerebral and coronary blood flow by this approach remains controversial. In animal models of ECLS in cardiac shock, adequate cerebral blood flow could be achieved by femoral as well as subclavian vascular access while coronary blood flow was increased by femoroarterial cannulation. Supplementary IABP revealed no benefit and showed a trend to be detrimental on coronary perfusion at least in mode of retrograde ECLS flow via femoral cannulation $[22,23]$. Other possibilities of reducing afterload have been discussed by the means of constructing an atrioseptal fistula, left ventricular venting as well as change to surgically inserted central cannulation [24].

Up to now, there are three other reported cases of resolving a typical "harlequin phenomenon". First, by switching to from femoroarterial to right-axillar cannulation [25] (similar to our case) or changing to VVA-ECLS [26]: Veno-venoarterial (VVA) cannulation by addition of a venous inflow cannula in ECLS combines the functional features of ECLS and ECMO and has been described as a feasible option in small studies [27]. Another successful approach consisted in moving the venous drainage from the lower to the upper vena cava $[19,28]$. Other theoretic options proposed for symptomatic treatment of unilateral hypoxia consist in intensifying mechanical ventilation or "moving the watershed" by increasing ECLS flow, using a longer arterial cannula to reach the aortic arch or switching to central surgical cannulation [29]. The proper mode of ventilation in patients 
on ECLS has not been elucidated in large studies up to now and moderate ventilator settings to allow "lung rest" are recommended [5]. Theoretically, full gas exchange via ECLS should enable maximum lung protection with adequate PEEP and low tidal volumes. However, PEEP has pleiotropic effects on cardiac output - patients with pulmonary edema might profit from increasing PEEP and intrathoracic pressure, while the increase of pulmonary vascular resistance might adversely affect patients with right ventricular failure. Thus, a pragmatical and reasonable approach to an adequate ventilator settings should be based on the underlying pathology as well as the mode of extracorporeal augmentation. In cases of cardiac recovery and persistent pulmonary insufficiency, a switch from ECLS to ECMO could be discussed. Because of repetitive phases of hemodynamic instability this step could not be performed in our patient. The problem of unilateral hypoxia could be resolved symptomatically by removing the femoroarterial cannula and intensification of mechanical ventilation.

Taken together, different pragmatic strategies can be discussed if sectorial hypoxia occurs in ECLS. Nevertheless, these strategies are all based on anectdotical or single case experience in patients requiring ECLS with different cannulation sites. In addition, the underlying pathologies leading to ECLS use must be taken into account and thus published solution strategies might not be transferred to every form of "harlequin phenomenon" without reflection. Case series, register data or clinical studies on many aspects of cannulation in ECLS including upstream hypoxia are lacking. The fact, that a sectorial hypoxia evolved even under the condition of additional arterial perfusion of the left upper quadrant implies that the underlying pathomechanism might be more complex than a "two-circuit-hypothesis" generated in an animal model [19]. Thus, hemodynamic optimization in "harlequin phenomenon" remains to be an individualized and tailored approach based on the supposed pathology. In our case of prolonged hemodynamic instability, the switch to single arterial cannulation via the right subclavian artery was successful in terminating sectorial hypoxia. From a pathophysiological point of view, intensification of mechanical ventilation was also reasonable. Perhaps, a "double" access via VVA-ECLS could have represented an interesting option though an effect on the eventual outcome remains doubtful.

\section{Conclusion}

ECLS and ECMO are established rescue therapies in lung and heart failure. Over the last years, promising data have been published emphasizing the relevance of extracorporeal augmenting systems in improving prognosis of these patients. Their availability has also amplified. Nevertheless, relevant side effects could be threatening and may limit the employment to a rescue therapy, especially in veno-arterial cannulation. Thus, extracorporeal augmenting systems should be implemented in specialized centers. Taken together the mode of veno-arterial access in ECLS remains an individual decision based on the preconditions of every single patient and the team experience. In accordance with the ELSO guidelines, it must be emphasized that the use of ECLS should be merely restricted to cardiocirculatory indications. Special attention has to be carefully turned on the specific vascular complications dependent on the site of cannulation.

\section{Compliance with ethical standards}

Conflict of interest All authors declared that they have no competing interests.

Funding None.

\section{References}

1. Zapol WM, Snider MT, Hill JD, Fallat RJ, Bartlett RH, Edmunds $\mathrm{LH}$, et al. Extracorporeal membrane oxygenation in severe acute respiratory failure. A randomizes prospective study. JAMA. 1979;242:2193-96.

2. Morris AH, Wallace CJ, Menlove RL, Clemmer TP, Orme JF Jr, Weaver LK, et al. Randomized clinical trial of pressure-controlled inverse ratio ventilation and extracorporeal CO2-Removal for adult respiratory distress syndrome. Am J Respir Crit Care Med. 1994;149:294-305.

3. Peek GJ, Mugford M, Tiruvoipati R, Wilson A, Allen E, Thalanany MM, et al. Efficacy and economic assessment of conventional ventilatory support versus extrcorporeal membrane oxygenation for severe adult respiratory failure (CESAR): a multicentre randomised controlled trial. The Lancet. 2009;374:1351-63.

4. Kuhl T, Michels G, Pfister R, Wendt S, Langebartels G, Wahlers $\mathrm{T}$. Comparison of the avalon dual-lumen cannula with conventional cannulation technique for venovenous extracorporeal membrane oxygenation. Thorac Cardiovasc Surg. 2015;63:653-62.

5. Extracorporeal life support organization. General guidelines for all ECLS cases version 1.3 November 2013. Extracorporeal life support organization, Ann Arbor. 2013. http://www.elso.org/ Resources/Guidelines.aspx. Accessed 16 Sep 2016.

6. Floerchinger B, Philipp A, Foltan M, Keyser A, Camboi D, Lubnow $M$, et al. Neuro-specific enolase serum levels predict severe neuronal injury after extracorporeal life support in resuscitation. Eur J Cardiothorac Surg. 2014;45:496-501.

7. Pfeifer R, Ferrari M, Figulla HR. Serumkonzentration der zerebralen Biomarker neuronenspezifische Enolase und Protein S100 B [German]. Intensivmed. 2011;48:207-15.

8. Extracorporeal life support organization: ECLS registry report international summary July 2016. Extracorporeal life support organization, Ann Arbor. 2016. http://www.elso.org/Registry/ Statistics/InternationalSummary.aspx. Accessed 16 Sep 2016.

9. Zangrillo A, Biondi-Zoccai G, Landoni G, Frati G, Patroniti N, Pesenti A, et al. Extracorporeal membrane oxygenation (ECMO) in patients with $\mathrm{H} 1 \mathrm{~N} 1$ influenza infection: a systematic review and meta-analysis including 8 studies and 266 patients receiving ECMO. Crit Care. 2013; 17:R30. 
10. Brodie D, Bacchetta M. Extracorporeal membrane oxygenation for ARDS in adults. New Engl J Med. 2011;365:1905-14.

11. Sidebotham D, McGeore A, McGuinness S, Edwards M, Will$\operatorname{cox}$ T, Beca J. Extracorporeal membrane oxygenation for treating severe cardiac and respiratory failure in adults: part 2-technical considerations. J Cardiothorac Vasc Anesth. 2010;24:164-72.

12. Paden ML, Conrad SA, Rycus PT, Thiagarajan RR, ELSO Registry. Extracorporeal life support organization registry report 2012. ASAIO J 2013;59:202-10.

13. Lunz D, Philipp A, Dolch M, Born F, Zausig YA. Venoarterial extracorporeal membrane oxygenation: indications, limitations and practical implementation. Anaesthesist 2014;63:625-35.

14. Benassi F, Vezzani A, Vignali L, Gherli T. Ultrasound guided femoral cannulation and percutaneous perfusion of the distal limb for VA ECMO. J Card Surg. 2014;29:427-29.

15. Takayama H, Landes E, Truby L, Fujita K, Kirtane AJ, Mongero $\mathrm{L}$, et al. Feasibility of smaller arterial cannulas in venoarterial extracorporeal membrane oxygenation. J Thorac Cardiovasc Surg. 2015; 149:1428-33.

16. Chamogeorgakis T, Lima B, Shafii AE, Nagpal D, Pokersnik JA, Navia JL, et al. Outcomes of axillary side graft cannulation for extracorporeal membrane oxygenation. J Thorac Cardiovasc Surg. 2013;145:1088-92.

17. Navia JL, Atik FA, Beyer EA, Ruda Vega P. Extracorporeal membrane oxygenation with right axillary artery perfusion. Ann Thorac Surg. 2005;79:2163-65.

18. Saeed D, Stosik H, Islamovic M, Albert A, Kamiya H, Maxhera $\mathrm{B}$, et al. Femoro-femoral versus atrio-aortic extracorporeal membrane oxygenation: selecting the ideal cannulation technique. Artif Organs. 2014;38:549 - 55.

19. Hou X, Yang X, Du Z, Xing J, Li H, Jiang C, et al. Superior vena cava drainage improves upper body oxygenation during venoarterial extracorporeal membrane oxygenation in sheep. Crit Care. 2015;19:68.

20. Beurtheret S, Mordant P, Pavie A, Leprince P. Impella and extracorporeal membrane oxygenation: a demanding combilation. ASAIO 2012;58:291-3.
21. Combes A, Bacchetta M, Brodie D, Müller T, Pellegrino V. Extracorporeal membrane oxygenation for respiratory failure in adults. Curr Opin Crit Care. 2012;18:99-104.

22. Bělohlávek J, Mlček M, Huptych M, Svoboda T, Havránek Š, Ošt'ádal P, et al. Coronary versus carotid blood flow and coronary perfusion pressure in a pig model of prolonged cardiac arrest treated by different modes of venoarterial ECMO and intraaortic balloon counterpulsation. Crit Care. 2012;16:R50.

23. Schroeter T, Vollroth M, Höbartner M, Sauer M, Mende M, Mohr $\mathrm{FW}$, et al. Influence of ECMO and IABP on coronary blood flow. Valuable combination or waste of resources? Med Klin Intensivmed Notfallmed. 2015;110:210-16.

24. Soleimani B, Pae WE. Management of left ventricular distension during peripheral extracoproeal membrane oxygenation for cardiogenic shock. Perfusion. 2012;27:326-31.

25. Fernandes P, Allen P, Valdis M, Guo L. Successful use of extracorporeal membrane oxygenation for pulmonary embolism, prolonged cardiac arrest, post partum: a cannulation dilemma. Perfusion. 2015;30:106-10.

26. Choi JH, Kim SW, Kim YU, Kim SY, Kim KS, Joo SJ, et al. Application of veno-arterial-venous extracorporeal membrane oxygenation in differential hypoxia. Mutidisc Respir Med. 2014;9:55.

27. Stöhr F, Emmert MY, Lachat ML, Stocker R, Maggiorini M, Falk $\mathrm{V}$, et al. Extracorporeal membrane oxygenation for acute respiratory distress syndrome: is the configuration mode an important predictor for the outcome? Interact Cardiovasc Throrac Surg. 2011;12:676 - 80

28. Lindfors M, Freckner B, Sartipy U, Bjällmark A, Broomé M. Venous cannula positioning in arterial deoxygenation during veno-arterial extracorporeal membrane oxygenation-a simulation study and case report. Artif Organs. 2017;41:75-81.

29. Annich G, MacLaren G, editors. Extracorporeal support in critical care. Ann Arbor: ELSO; 2012. pp. 152, 327-8. 